\title{
Points Without Limits: Individual Inquiry, Collaborative Investigation, and Collective Scholarship
}

\author{
Richard A. Gale \\ The Carnegie Foundation for the Advancement of Teaching
}

This chapter proposes that a scholarship of teaching and learning focused on collaborative and collective inquiry can be more effective and have greater impact on student learning and the advancement of knowledge than investigations accomplished by individual faculty and students working in isolation. This conclusion is arrived at as a result of examining the work of Carnegie Scholars and the Carnegie Academy for the Scholarship of Teaching and Learning Campus Program participants since 1998.

There is a perspective about the practice of scholarship that celebrates the work of the individual over the collective. From this point of view, scholarly pursuit is solitary pursuit, exemplified by isolated investigation, idiosyncratic discovery, and individual genius. But virtually all scholarship requires some collaborative effort, and the most important insights tend to result from the most collective endeavors. Such is the case with the scholarship of teaching and learning, which not only thrives on association but strives for the abolition of pedagogical solitude. Even when acknowledged as a communal act, the scholarship of teaching and learning is often viewed in terms of individual faculty members working within the microclimates of their own classrooms. Teaching and learning scholars are seen as reaching out to larger audiences for the purpose of dissemination and review, but not for the processes and practices of inquiry. This tendency may be an artifact of the tenure and promotion 
process, which clearly privileges individual over communal efforts, but it might also result from a too-limited view of what it means to imagine, engage in, and produce scholarship. For although much ground is to be gained from the work of individual faculty conducting focused inquiry into student learning, even more mileage can be achieved when two or more scholars work collaboratively, and the distance that can be covered by collective approaches to scholarship (within the department, program, school, institution, and system) is certainly significant, if not "without limits."

In his book Arctic Dreams (1986), Barry Lopez devotes a lyrical and informative chapter to the mythology, history, biology, and social significance of the narwhal, a (perhaps magical) creature with the appearance of a piketipped torpedo, whose pronounced tooth was traded as a unicorn horn in the Middle Ages, and whose very existence has been a source of doubt and legend and misunderstanding for generations. While Lopez offers a good deal of history, science, and lore to help readers understand this member of the whale family, what stands at the heart of his chapter is the value of shared understanding brought to bear on what can only be described as an enduring mystery. Lopez engages the reader with the idea of how observation, investigation, examination, and application all combine, under the right conditions, to create knowledge that leads to action.

Because you have seen something doesn't mean you can explain it. Differing interpretations will always abound, even when good minds come to bear. The kernel of indisputable information is a dot in space; interpretations grow out of the desire to make this point a line, to give it a direction. The directions in which it can be sent, the uses to which it can be put by a culturally, professionally, and geographically diverse society, are almost without limit. (Lopez, 1986, p. 127)

This idea can be applied to the more general process by which we see and understand anything in the world. It begins with the perceived: an observation, or the simple act of seeing. When seeing is coupled with inquiry, the process of investigation begins, and we have the toehold of "indisputable information," or "a dot in space" with meaning, if not with magnitude. Investigation leads to interpretation, which when combined and coordinated with other interpretations creates a line, a point with direction that not only indicates source but predicts the future and can hence be put to use by the aforementioned "culturally, professionally, and geographically diverse society." This is the process that leads to knowledge building. This is also the course of scholarship, and the way in which investigation moves from individual, to col- 
laborative (between individuals), to collective (involving systematic or institutionally structured) inquiry.

Whether the object at hand is (with apologies to Hamlet) a whale or a weasel, a hawk or a handsaw, the necessities of discovery require that what is seen be documented, what is evident be backed by evidence, what serves as proof be subject to corroboration and evaluation, and what is reviewed be made public for additional analysis and future expansive use. Such is the established pattern of scholarship within the realm of disciplinary journals and professional publications of all kinds. This scenario also serves as well for the scholarship of teaching and learning, which has grown into a global movement with its own dedicated publication outlets, an international society, and widespread currency on campuses around the world. All of this was made possible through the work of individual students, faculty, and administrators, campus teams and centers for teaching and learning, and broad coalitions of institutional and disciplinary partners. Furthermore, whether inquiry is solitary, shared, or formally coordinated, what sits foursquare at the center of this scholarship is evidence of student learning.

\section{Individual Inquiry}

Individual inquiry forms the bedrock of the scholarship of teaching and learning, for this process begins with attempts to understand and improve student learning in specific curricular contexts. Yet as with all intellectual work of scope and scale, the scholarship of teaching and learning seeks not to improve one classroom context but to add knowledge to the field and thereby have an impact on how students learn and how faculty teach in multiple educational contexts. Through the gathering of evidence of student learning, the investigation of classroom teaching, and the peer review of significant results, this scholarship seeks to expand the landscape of understanding within and beyond a specific pedagogical or disciplinary context. It utilizes a cycle of inquiry involving observation, investigation, examination, and application: taking note of some aspect of student learning, constructing an inquiry project to gather evidence informing that observation, making the results available for peer review, and going public so that new knowledge can inform practice and make change beyond the local. This represents the most prevalent form of the scholarship of teaching and learning, and the place where most individual scholars of student learning begin. However, if the goal is a better understanding of how students learn, with an eye to changing teaching practice for the better, then individual inquiry cannot be the end of the process, even if it is made public and "passed along" to other interested and influential audiences. 
When most effective, individual inquiry leads to application within the discipline, the department, the institution, and beyond-sparking additional individual inquiry or, when possible, collaborative investigation.

\section{Collaborative Investigation}

Collaborative investigation might be described not as "many hands make light work" but rather as "two or more heads are better than one." The premise is that collaborative efforts among two or more scholars produce additional evidence, improved insight, and more meaningful results (a position that is now almost commonplace, well documented, and verified in the extensive research on collaborative work but not entirely transparent in the literature on the scholarship of teaching and learning). These collaborations might take several forms, but in general they can be categorized according to the questions asked and the settings in which they take place. Questions might be identical (common), linked in some concrete and logical way (connected), or sufficiently similar so that they can be put side by side and yield meaning (comparable). Likewise, settings might be common (the same course), connected (courses in sequence or in tandem), or comparable (the same course within another department or at another institution). In thinking about this approach to collaborative investigation, the real issue is the evidence generated, and one way of thinking about evidence in a collaborative inquiry environment is represented in Table 3.1.

TABLE 3.1

Collaborative Investigation Settings, Questions, and Evidence

\begin{tabular}{|l|l|l|l|}
\hline & \multicolumn{1}{|c|}{$\begin{array}{c}\text { Common } \\
\text { Questions }\end{array}$} & \multicolumn{1}{c|}{$\begin{array}{c}\text { Connected } \\
\text { Questions }\end{array}$} & \multicolumn{1}{|c|}{$\begin{array}{c}\text { Comparable } \\
\text { Questions }\end{array}$} \\
\hline Common Settings & Common evidence & Connected evidence & Comparable evidence \\
\hline Connected Settings & Connected evidence & Connected evidence & Comparable evidence \\
\hline $\begin{array}{l}\text { Comparable } \\
\text { Settings }\end{array}$ & $\begin{array}{l}\text { Comparable } \\
\text { evidence }\end{array}$ & Comparable evidence & $\begin{array}{l}\text { Complementary, not } \\
\text { comparable, evidence }\end{array}$ \\
\hline
\end{tabular}

When two or more scholars share both question and setting (e.g., how students learn to integrate life experience into two different sections of a Great Books course) the evidence yielded can be viewed as a common set. When scholars' questions are common (integrating life experience), but the settings 
are not (connected, as in sequential Great Books courses at the same institution, or comparable, as in the same course at another institution), the evidence can be viewed as either connected or comparable, but not as common. However, when both questions and settings are merely comparable (perhaps with one scholar examining the integration of life experience into a Great Books course and the other examining the integration of cocurricular experiences into a modern literature course, or two scholars working at very different kinds of institutions), the evidence must be viewed as complementary, not comparable-informative but not supportive. Such complementary evidence might inform the individual research of each scholar, but the results would be too dissimilar to serve as a true collaboration.

One example of paired inquiry (common, connected, and perhaps comparable as well) can be found in the team-based approaches of Gerald Shenk and David Takacs at California State University-Monterey Bay, who were interested in how students acquire new historical understanding and use that knowledge to inform political action and ongoing civic engagement. They used the common setting of a team-taught course and common questions, jointly developed, to produce common evidence of student learning. That evidence was collected and evaluated jointly, with the different perspectives of the two scholars (the former from history and the latter from environmental studies) producing a triangulation of analysis, as well as a combination of research methodologies from two different disciplinary practices. The paired inquiry resulted in a broader sense of the student work and in a clearer interpretation of student learning (Shenk, 2001; Takacs, 2001).

Catherine Berheide and Michael Marx at Skidmore College took a similar approach to their team investigation of the habits of mind that lead students to critical thinking, and of the metacognitive strategies that contribute to deep and persistent learning. They created an Idea Notebook to help students understand their own responses to course materials, thus bringing to the surface students' cognitive processes:

One of the common goals of a college education is to develop students' critical thinking skills. We designed the Idea Notebook-a semesterlong activity asking students to reflect on their thought processes--to promote critical thinking. We piloted it in an honors course for sophomores serving as tutors in Liberal Studies 1: Human Dilemmas, Skidmore College's required first-year seminar. (Berheide \& Marx, 2004)

Their collaboration focused on the recognition of a common observation, the development of a connected question, and then the application of that strategy to connected settings. 
One project under way at this writing involves chemistry faculty at Carleton and Hope colleges (Tricia Ferrett and Joanne Stewart, respectively) adopting a decidedly hybrid approach to looking at how students integrate multiple scientific perspectives, social and political influences, and religious predispositions around the topic of abrupt climate change. Teaching two similar courses on two different campuses in sequential terms, this collaborative pairing of scholars provides a unique opportunity to see the ways in which student learning can be observed in comparable settings, with initially common questions, yielding evidence that is interpreted by two informed investigators with complementary interests (Ferrett, 2006; Stewart, 2006). The results of this initial investigation are then applied to a new context, one with shared origins and questions, but distinctly different circumstances, producing a very different but somehow connected dataset that can be compared with the original evidence. Together, the two currents of evidence create a confluence of understanding, almost estuarial in its mixed yet unmixed nature.

Joanne and I... can now articulate which questions we share (what does integrative science learning look like in the context of our courses, different context, student ages and populations) and which ones are unique to our institutional project (Joanne's bit on how students combine who they are with science learning and beliefs and values). And we are both working hard together on describing the pedagogy which we share, and the developmental aspects of student learning that are emerging in our evidence. (T. Ferrett, personal communication, May 26, 2006)

It is a complicated process, difficult to keep in alignment, but the results of this pairing will likely be a much richer and more realistic sense of how student learning can inform a developing teaching practice.

In all of these, the goal has been to make the strongest case possible based on correlated evidence from more than one source, gathered in a collaborative manner, and coordinated for collaborative purposes. Another approach to collaboration involves faculty partnering with students to answer important questions about learning. This strategy can also take the forms mentioned earlier and has added pedagogical benefits for all involved, especially in terms of the collateral impact that such collaboration has on the students who often go on from an initial inquiry to become more intentional about their own learning processes. Perhaps the best examples of this kind of collaboration can be found at institutions like Western Washington University, where faculty and students have been working together under the auspices of the TeachingLearning Academy to develop comparable questions in common settings, and 
North Seattle Community College, where students have taken the initiative to create inquiry tools for asking important learning questions across institutional contexts. My own introduction to the scholarship of teaching and learning was in the form of student collaboration, while a 2000-2001 Carnegie Scholar at Sonoma State University, where I worked with student investigators to develop a unified question set and group of inquiry tools to learn how students were using a program portfolio for the purposes of intentional learning (Gale, 2003). Regardless of the form, these collaborative approaches, shown in Table 3.2, serve to advance the knowledge of student learning and the practice of thoughtful and reflective teaching, while also building a particular kind of scholarly community around issues of importance to classrooms everywhere.

TABLE 3.2

Examples of Collaborative Investigation

\begin{tabular}{|c|c|c|c|}
\hline & $\begin{array}{l}\text { Common } \\
\text { Questions }\end{array}$ & $\begin{array}{l}\text { Connected } \\
\text { Questions }\end{array}$ & $\begin{array}{c}\text { Comparable } \\
\text { Questions }\end{array}$ \\
\hline $\begin{array}{l}\text { Common } \\
\text { Settings }\end{array}$ & $\begin{array}{l}\text { How students acquire } \\
\text { new historical under- } \\
\text { standing and use that } \\
\text { knowledge to inform } \\
\text { political action and } \\
\text { ongoing civic engage- } \\
\text { ment }\end{array}$ & $\begin{array}{l}\text { How students use pro- } \\
\text { gram portfolios for the } \\
\text { purposes of intentional } \\
\text { learning }\end{array}$ & $\begin{array}{l}\text { Students working to- } \\
\text { gether to develop com- } \\
\text { parable questions in } \\
\text { common settings }\end{array}$ \\
\hline $\begin{array}{l}\text { Connected } \\
\text { Settings }\end{array}$ & & $\begin{array}{l}\text { Habits of mind that } \\
\text { lead students to critical } \\
\text { thinking, and of the } \\
\text { metacognitive strate- } \\
\text { gies that contribute to } \\
\text { deep and persistent } \\
\text { learning }\end{array}$ & $\begin{array}{l}\text { Students creating in- } \\
\text { quiry tools for asking } \\
\text { important learning } \\
\text { questions across insti- } \\
\text { tutional contexts }\end{array}$ \\
\hline $\begin{array}{l}\text { Comparable } \\
\text { Settings }\end{array}$ & & & $\begin{array}{l}\text { How students inte- } \\
\text { grate multiple scien- } \\
\text { tific perspectives, } \\
\text { social and political in- } \\
\text { fluences, and religious } \\
\text { predispositions } \\
\text { around the topic of } \\
\text { abrupt climate change }\end{array}$ \\
\hline
\end{tabular}




\section{Collective Scholarship}

Yet what if this approach to collaboration were taken to the next level of complexity and incorporated into structures and communities already in existence? What if inquiry were shared not only among individual scholars, but among an entire department, college, or university system? This is the premise behind collective scholarship, which seeks to ask the question: What can we learn in concert that we cannot learn as well, or at all, in isolation? For if collaboration among individual scholars can produce deeper understanding and improved practice, then surely collective scholarship within a program, a discipline, or even a regional network of campuses might yield the answers to significant shared questions.

Like the collaborative investigations described earlier, collective scholarship relies on the work of individual scholars conducting inquiry projects in local settings. But unlike these collaborations, collective inquiry is based on a coordinated and aggregating philosophy wherein multiple inquiry projects, configured in different settings and from different investigative standpoints, all have as their objective a deeper understanding of a communal question. Such collective inquiry requires a substantial level of coordination-coordinated goals, investigations, evidence gathering, and dissemination. Its benefits are just as substantial, indeed, perhaps more so, because they address directly and consistently one of the central difficulties of the scholarship of teaching and learning-going public and passing on the results of the investigation. Collective scholarship begins with a single question asked across a community, builds on the knowledge and experience within that same community, shares evidence and application throughout the community, and then asks all of the members to be involved in more widespread dissemination. Such scholarship, when coordinated, has the potential to yield comparable and complimentary evidence that can in turn influence programmatic, institutional, and trans-institutional understanding of student learning, as suggested in Table 3.3 and the following examples.

Examples of this kind of inquiry are more nascent, but often early steps provide a valuable window into what can be accomplished through a more structural and collective scholarship of teaching and learning. At Gustavus Adolphus College, the Department of History has embarked on a collective scholarship project, coordinated among the faculty and connected to multiple courses, that seeks to answer the question: "How are our students learning to think like historians?" (Huber \& Hutchings, 2005, p. 81). This distinctly disciplinary question is being asked within a programmatic context that will, hopefully, yield evidence of how local learning informs and is informed by 
TABLE 3.3

Collective Scholarship Settings, Inquiry, and Evidence

\begin{tabular}{|l|l|l|l|}
\hline & $\begin{array}{c}\text { Mission-Oriented } \\
\text { Inquiry }\end{array}$ & $\begin{array}{l}\text { Mandate- or Policy- } \\
\text { Driven Inquiry }\end{array}$ & \multicolumn{1}{|c|}{$\begin{array}{c}\text { Metacognitive } \\
\text { Inquiry }\end{array}$} \\
\hline $\begin{array}{l}\text { Department or } \\
\text { Program Level }\end{array}$ & $\begin{array}{l}\text { Programmatic } \\
\text { evidence }\end{array}$ & $\begin{array}{l}\text { Institutional } \\
\text { evidence }\end{array}$ & $\begin{array}{l}\text { Trans-institutional } \\
\text { evidence }\end{array}$ \\
\hline $\begin{array}{l}\text { Institution or } \\
\text { Discipline Level }\end{array}$ & $\begin{array}{l}\text { Institutional } \\
\text { evidence }\end{array}$ & $\begin{array}{l}\text { Institutional } \\
\text { evidence }\end{array}$ & $\begin{array}{l}\text { Trans-institutional } \\
\text { evidence }\end{array}$ \\
\hline $\begin{array}{l}\text { System-Wide or } \\
\text { Regional Level }\end{array}$ & $\begin{array}{l}\text { Trans-institutional } \\
\text { evidence }\end{array}$ & $\begin{array}{l}\text { Trans-institutional } \\
\text { evidence }\end{array}$ & $\begin{array}{l}\text { Trans-institutional } \\
\text { evidence }\end{array}$ \\
\hline
\end{tabular}

disciplinary understanding. Similarly, the Center of Inquiry in the Liberal Arts at Wabash College has, in a series of workshops and presentations, challenged colleagues to turn their scholarly attention to what makes student learning in the liberal arts distinctive, what makes their experience different and (most believe) better. While institutional in scope and mission oriented in focus, this inquiry will produce not only institutional evidence, but perhaps a framework for use within other liberal arts settings, thus expanding the reach to a transinstitutional level.

At a 2005 gathering in Washington, DC, representatives of three biological science disciplinary societies discussed and began planning for a collective inquiry into the teaching and learning of evolution using a coherent group of committed individuals to better understand what is essentially a policy issue. Perhaps most significant, because it is so rare, the University of Wisconsin System recently instituted a collective scholarship project designed to better understand student learning in the creative, fine, and performing arts. This project, coordinated through the Office of Professional and Instructional Development, builds on the depth of knowledge developed by faculty in the University of Wisconsin System and on its commitment to the scholarship of teaching and learning, while also acknowledging that more needs to be understood about how students learn aesthetic literacy, creative confidence, and other important capacities found in arts disciplines. This trans-institutional collaboration will certainly produce evidence that has applicability beyond the institutions of the system itself, and in that way becomes perhaps omniinstitutional in its impact.

Less obvious might be the categories under which these examples operate, the forms such collective scholarship might take. As Table 3.3 suggests, there are three types of inquiry that seem particularly well suited to the ways and means and outcomes of collective scholarship. Mission-oriented inquiry 
is generally directed at one of two questions: Who are you? or Who do you want to be? Collective scholarship of this sort seeks to address changing or uncertain institutional identity and aspirations, concerns about student engagement with campus values, or the impact of signature programs. Mandate- or policy-driven inquiry uses the scholarship of teaching and learning to respond to external influences such as accreditation reviews or calls for accountability and increased productivity, or to address internal reevaluation of what matters, such as diversity initiatives, program development, or student retention. Metacognitive inquiry tries to address issues with wider implications; it also attempts to build knowledge across multiple contexts by understanding what students learn (aesthetic literacy, integrative perspectives, quantitative reasoning), how students learn (the academic seminar, field experience, service-learning, study abroad), or why students learn (ethical reasoning, political engagement, world citizenship). Therefore, a mission-oriented inquiry at the system-wide level might include collective scholarship focusing on successful integration of disciplinary knowledge and local service-learning opportunities in senior capstone courses. Likewise, a mandate-driven inquiry at the program level might involve investigation of how required electronic portfolios help students transition from general education to the major. Finally, a metacognitive inquiry could range from the examination of how mapping software impacts global literacy in an honors seminar (program level), to how study abroad influences global awareness among seniors (institution level) or sociologists (discipline level).

These brief and often speculative examples remind us that the scholarship of teaching and learning is perhaps most effective and most likely to contribute to the academic culture and intellectual advancement of a department, campus, and so on when it is integrated into ongoing initiatives and preexisting structures, or when linked to other data sources already being used at the institutional level (National Survey of Student Engagement, Collegiate Learning Assessment, etc., as well as home-grown surveys and information-gathering mechanisms). Likewise, it brings to the fore one of the central issues surrounding work in the scholarship of teaching and learning: institutional support and scaffolding. All those who have engaged in this form of inquiry understand the need for validation and valorization of teaching and learning scholarship; indeed, the question of how such scholarship is valued by departmental and campus colleagues in the retention, tenure, and promotion process has always been important and is far from being resolved in most settings. At many institutions, the key to support has been the creation of infrastructure: establishing a center for teaching and learning that has part of its mandate the encouragement of inquiry into student learning; creating dedi- 
cated pathways and conduits for classroom investigation with dedicated (ongoing) funding sources, mentoring opportunities, and dissemination vehicles; building a culture of inquiry that exposes all faculty to this kind of scholarship, provides multiple opportunities for asking questions and sharing results, and celebrates the accomplishments of teaching and learning scholars.

This is particularly important when approaching the challenges of collective scholarship, and in fact might be more likely and more fruitful under those circumstances. Obviously, pursuing this kind of inquiry directly benefits the students, faculty, and others on a campus or within a system. This is especially true when the investigation addresses a felt need or an institutional mandate. It also helps expand the knowledge and practice of the scholarship of teaching and learning such that individuals might build on their experiences and create new kinds of inquiry beyond the collective; in this way, collective scholarship strengthens and encourages collaborative and individual inquiry. But more than that, collective inquiry supports and nurtures the internal/institutional, disciplinary, and international community of scholars, forging connections and building networks within to what Mary Taylor Huber and Pat Hutchings (2005) have termed the teaching commons.

Of course, the use of the term commons for the shared space of ideas is, if you will, quite common, and has gained particular currency in the 21 st-century world of new media and online communications; nevertheless, it is a useful designation for the overlapping work of teaching, learning, and scholarly pedagogical inquiry. The teaching commons, as described by Huber and Hutchings, is a place (occasionally physical, usually metaphorical, and often virtual) where "communities of educators committed to pedagogical inquiry and innovation come together to exchange ideas about teaching and learning, and use them to meet the challenges of educating students for personal, professional, and civic life in the twenty-first century" ( $p . x)$. This sense of the commons spans as far and wide as the imagination can reach, including students, faculty, and administrators and staff committed to its ideals, and encompassing much of the practice of teaching and learning, as well as all of its scholarship. But central to the commons is that it is made up of nested communities, and that the totality (if such an amorphous and changeable thing can ever be in toto) is made up not of parts, but of other wholes. Thus, collective scholarship builds on and creates a teaching commons for the department or program, institution or discipline, system or region that chooses to take on the inquiry and organize the intellectual capital to see it through. Aside from breaking down the pedagogical solitude of most faculty, this view of a commons is the natural next step, the structural manifestation of teaching and scholarship as community property first proposed by Lee Shulman (1993). 
This, in turn, harkens back to Ernest Boyer's Scholarship Reconsidered (1990) which proposed "a shared vision of intellectual and social possibilities-a community of scholars" engaged in a "campuswide, collaborative effort around teaching," and championed "cooperative research" because "investigators talk increasingly about 'networks of knowledge,' even as individual creativity is recognized and affirmed" (p. 80).

\section{Conclusion}

Boyer's reminder about networks and the individual is as true today as it was then. But the kind of collective work described here requires more than a group of committed experts, and more than a local view of learning and scholarship. It is premised on strong pedagogical leadership; leadership with a vision or ideology based on knowledge and practice, supported by incentives or rewards and tempered by critical judgment, enhanced through the process of reflection and the involvement of a thoughtful community (Shulman, 2004). Such leadership develops out of an intimate knowledge of place and purpose, an empathetic understanding of the work of faculty and students, and above all from a clear and discerning sense of what has been, what is, and what can be. Leaders of this sort might hold positions of prominence within departments or colleges or systems, but they might also be found within a changing student body or a faculty subcommittee. Educational leaders support this kind of scholarship through structural means such as the organization of peer-review panels and the revision of tenure guidelines, but they also work below the radar through campus conversations and student learning initiatives. The who and the where are variable, and not nearly as important as the what and the when and the how. With that said, however, it must be acknowledged that several questions remain: How can educational leaders (variously defined) influence the culture of an institution? What will be the nature and source of support for this kind of scholarship? Where can faculty (and graduate students and administrators) begin? The answers are often bound to institutional culture, disciplinary predisposition, and the vagaries of higher education economics. But they are also the starting point for a broader understanding of student learning, faculty work, and campus accountability.

All of this suggests a longer view of learning and teaching and scholarship, and a more coherent and directed sense of community and common cause. Much of the work of the scholarship of teaching and learning has been local and small scale-individual faculty pursuing bounded inquiry from which they hope to make a difference. Often this kind of scholarship begins with intellectual curiosity and the desire to make things better (or at least dif- 
ferent) in a teacher's own classroom. This is a noble pursuit, and when made available for peer review and public use, such endeavors are the foundation of knowledge building and pedagogical improvement. But with collaborative and especially collective scholarship, the focus shifts dramatically and intentionally to a place outside the local. The question becomes not, What would make this course better? or, Is this working in my class? or, How do I think about assessing for this? Instead, it becomes, Will this lead to better student learning in the department and the discipline? or, How does this fit with the larger curricular goals of the institution? or, What gets assessed, and why, and how often?

Change has always been the goal of the scholarship of teaching and learning: deeper understanding of the processes of student learning; clearer knowledge of what contributes to better student learning; more imaginative approaches to learning from student learning. But that devotion to change has, as its corollary, a commitment to broad-based, widespread, and longranging improvement beyond the single classroom, department, or campus. And while the effort of individuals will always be at the heart of this and all forms of scholarship, it is the coordinated work of scholars, students, and administrators sharing communal goals, processes, and evidence that will ultimately bring the most light to the often opaque environment of student learning.

As Lopez (1986) suggested, our curiosity and commitment and desire for change always begins as a single point; and scholarship that remains in place exists forever as a point in space, without breadth or trajectory or influence. But when isolated inquiry becomes scholarship, when investigation becomes public, that point becomes a line with scale and purpose and significance. Geometry teaches us that there is another stage, a way in which multiple lines combine to form a plane that reaches to infinity. And this is what we are about when we move the scholarship of teaching and learning beyond the local, the individual, even the collaborative. It is the moment when lines become landscape, when direction becomes dimension, and when insight becomes impact that can change teaching and learning practice writ small and large, locally and beyond, now and into the future. 


\section{References}

Berheide, C. W., \& Marx, M. S. (2004). Thinking about thinking: Using an Idea Notebook to develop critical thinking skills. Retrieved May 14, 2007, from www.cfkeep .org/html/snapshot.php?id=68820745934565

Boyer, E. L. (1990). Scholarship reconsidered: Priorities of the professoriate. Princeton, NJ: The Carnegie Foundation for the Advancement of Teaching.

Ferrett, T. (2006). First year students "go beyond" with integrative inquiry into abrupt change. Retrieved May 14, 2007, from www.cfkeep.org/html/snapshot .php?id=28615862064637

Gale, R. (2003). Portfolio assessment and student empowerment. Retrieved May 14, 2007, from www.cfkeep.org/html/snapshot.php?id $=2478563$

Huber, M. T., \& Hutchings, P. (2005). The advancement of learning: Building the teaching commons. San Francisco, CA: Jossey-Bass.

Lopez, B. (1986). Arctic dreams. New York, NY: Vintage Books.

Shenk, G. (2001). California history and political action. Retrieved May 14, 2007, from www.carnegiefoundation.org/programs/project_summary.asp?scholar $=114$

Shulman, L. S. (1993, November/December). Teaching as community property: Putting an end to pedagogical solitude. Change, 25(6), 6-7.

Shulman, L. S. (2004). Visions of educational leadership: Sustaining the legacy of Seymour Fox. In M. Nisan \& O. Schremer (Eds.), Educational deliberations: Festschrift in honor of Seymour M. Fox (pp. 451-472). Jerusalem: Keter Publishers.

Stewart, J. L. (2006). Integrative learning in the sciences: Decision making at the intersection of science knowledge and student beliefs and values. Retrieved May 14, 2007, from www.ckeep.org/html/snapshot.php?id=70824690508493

Takacs, D. (2001). Teaching to inspire political participation in communities. Retrieved May 14, 2007, from www.carnegiefoundation.org/programs/project_summary .asp?scholar $=115$ 